\title{
More than wheezing: incorporating social determinants into public policy to improve asthma outcomes in children
}

\author{
Jean L. Raphael1,2, Jeffrey D. Colvin ${ }^{3}$; Pediatric Policy Council
}

$E_{t}^{\text {tin }}$ forts to improve child health in the United States have historically positioned the health care system as the focal point for transformative change. With passage of the Affordable Care Act, there have been increasing initiatives to address factors outside the health care system and reform payments to incentivize broader approaches to health. Social determinants of health $(\mathrm{SDH})$ offers a promising approach to translate research from various sectors into cohesive public policy efforts to impact health outcomes (1). The SDH are defined as the circumstances in which people are born, grow up, live, work, and age, that affect a wide range of health, functioning, and quality-of-life outcomes and risks. Within this model, the health care sector represents merely one component influencing health and health outcomes. Various conditions (e.g., social, economic, built environment) and sectors (e.g., business, education, policing) also play critical roles. In this issue, Gargano et al. (2) report on asthma control in adolescents a decade after exposure to the World Trade Center disaster. The authors highlight the association between different SDH and asthma control. Lower household income was associated with worse asthma control. According to the authors, poverty may reduce access to care which in turn impacts ability to effectively control asthma. Adolescents who screened positive for at least one mental health condition had six times the odds of having poorly/very poorly controlled asthma. The authors postulate a number of mechanisms by which this relationship may occur, including mental health conditions impacting the ability to cope with asthma or mental health symptoms interfering with adherence to medical treatment for respiratory symptoms. While studies such as this article represents critical milestones in understanding the cumulative influence of SDH on asthma control, translating evidence into public policy to affect asthma outcomes for children requires more cross-sector study and multi-pronged strategies.

The medical literature on asthma in children has long considered the contributions of SDH on outcomes (3-7). Numerous studies have documented a wide range of SDH factors influencing asthma risk for children. Although the connections between those factors have yet to be fully discerned, they inevitably lead to multi-sector policy solutions. For instance, poor housing conditions (e.g., cockroach infestations, residential

crowding), which may predispose residents to viral illnesses and subsequent asthma exacerbations, posit direct causation between SDH and asthma risk (8). However, evidence suggests that factors such as housing conditions do not fully account for the distribution of asthma risk (3). Other, less direct, factors such as caretaker mental health, community violence, and the built environment have been shown to play as large a role, if not larger, in asthma expression $(6,7,9,10)$. How these conditions are interrelated and reinforcing, such as through increased stress, and which are most important to be targeted through policy solutions remains to be elucidated. What is clear, however, is that the most promising policy solutions will likely fall outside the health care realm and will require physicians and other members of the health care team to engage collaborators from multiple sectors, such as housing, city development, and policing.

The Kaiser Family Foundation recently highlighted a number of policy strategies taking a multi-sector approach to address SDH (11). Several of these strategies are applicable to childhood asthma. Mapping and place-based strategies are increasingly used to identify populations at risk for poor health outcomes. In a study by Beck et al. (12), a geographic social risk index was found to identify hospitalized children with asthma likely to have an asthma-related readmission or return to the emergency department. This information could be used to tailor precise patient-specific interventions before discharge or be incorporated into the chronic asthma action plan. On a more global scale, geographic information can be used to inform place-based approaches that identify high-risk communities and targets for intervention (13). Beck et al. also demonstrated that hospitalized children with asthma can be aggregated at the geographic level to direct efforts impacting multiple patients, such as enforcement of the housing code through the use of medical-legal partnerships and through collaboration with community-based organizations $(14,15)$.

In the public health community, there has been a growing movement towards a "Health in All Policies" approach (16). This strategy comprises a collaborative approach to improve health by incorporating health considerations into decisionmaking across sector and policy areas. A Health in All Policies approach identifies the ways in which decisions in various

'Department of Pediatrics, Baylor College of Medicine, Houston, Texas; ${ }^{2}$ Center for Child Health Policy and Advocacy, Baylor College of Medicine, Houston, Texas;

${ }^{3}$ Department of Pediatrics, The Children's Mercy Hospital and Clinics, Kansas City, Missouri. Correspondence: Jean L. Raphael (Raphael@bcm.edu)

Advance online publication 16 November 2016. doi:10.1038/pr.2016.223 
sectors impact health and how better health can promote the aims of these multiple sectors. The National Prevention Council, created by the Affordable Care Act, convenes leaders from 20 federal departments, agencies, and offices to develop shared health priorities. Such approaches are also being replicated at the state level. In 2010, California established a Health in All Policies Task Force composed of leaders from various sectors. For asthma, a Health in All Policies approach would potentially influence decisions on education, housing codes, crime prevention, and location of transit lines. As an example, education policies could prioritize asthma management in the school system. Examples would include asthma education for school personnel, limitation of bus idling time, and banning of pesticides inside school when students are present (17).

Efforts are also emerging to integrate social determinants into health care. Through the State Innovation Models Initiative (18), a program operated by the Center for Medicare and Medicaid Innovation, states are engaged in multi-payer delivery and payment reforms that focus on population health and SDH. Many of the states receiving grants through the State Innovation Models Initiative have incorporated plans to address SDH (11). These plans include more active connection to community resources and coordinated activities across health care providers and health plans, public health agencies, local government, and social service agencies. In many cases, payments are adjusted to prioritize services that support care for the whole person. The Center for Medicare and Medicaid has also created the Accountable Health Communities Model (19). The premise of this model is that unmet health-related social needs, such as food insecurity and inadequate housing, may increase the risk of developing chronic conditions, reduce an individual's ability to manage their condition, increase health care expenditures, and lead to avoidable health care use. This model tests whether systematically identifying and addressing the health-related social needs of beneficiaries impact total health care costs, improves health, and enhances quality of care. CMS will award cooperative agreements to implement the Accountable Health Communities model across the country. Integrating SDH into health care could have wide ranging applications for asthma. This may include more focus on environmental controls and housing in routine care.

With increasing awareness of SDH as a powerful mechanism in health and health care and new opportunities afforded through the Affordable Care Act, the potential to translate the evidence on asthma outcomes among children into public policy is unprecedented. Shared priorities and coordination across different sectors will facilitate multi-level strategies and solutions not previously considered or possible. Consequently, asthma can serve as a test model of how to incorporate SDH into public policy for other chronic conditions impacting children.
Disclosure: The authors have no financial relationships relevant to this article to disclose. The authors have no conflicts of interest to disclose.

\section{REFERENCES}

1. Healthy People 2020: Social Determinants of Health. Accessed 10 August 2016. http://www.healthypeople.gov/2020/topics-objectives/topic/socialdeterminants-health.

2. Gargano LM, Thomas PA, Stellman SD. Asthma control in adolescents 10 to $11 \mathrm{y}$ after exposure to the World Trade Center disaster. Pediatr Res 2016; e-pub ahead of print 26 October 2016.

3. Williams DR, Sternthal M, Wright RJ. Social determinants: taking the social context of asthma seriously. Pediatrics 2009;123 Suppl 3:S174-84.

4. Jackson B, Kubzansky LD, Cohen S, Weiss S, Wright RJ; CARDIA Study. A matter of life and breath: childhood socioeconomic status is related to young adult pulmonary function in the CARDIA study. Int J Epidemiol 2004;33:271-8.

5. Sandel M, Wright RJ. When home is where the stress is: expanding the dimensions of housing that influence asthma morbidity. Arch Dis Child 2006;91:942-8.

6. Wright RJ, Cohen RT, Cohen S. The impact of stress on the development and expression of atopy. Curr Opin Allergy Clin Immunol 2005;5:23-9.

7. Wade S, Weil C, Holden G, et al. Psychosocial characteristics of inner-city children with asthma: a description of the NCICAS psychosocial protocol. National Cooperative Inner-City Asthma Study. Pediatr Pulmonol 1997;24:263-76.

8. Rosenstreich DL, Eggleston P, Kattan M, et al. The role of cockroach allergy and exposure to cockroach allergen in causing morbidity among inner-city children with asthma. N Engl J Med 1997;336:1356-63.

9. Beck AF, Huang B, Ryan PH, Sandel MT, Chen C, Kahn RS. Areas with high rates of police-reported violent crime have higher rates of childhood asthma morbidity. J Pediatr 2016;173:175-182.e1.

10. Wright RJ. Health effects of socially toxic neighborhoods: the violence and urban asthma paradigm. Clin Chest Med 2006;27:413-21, v.

11. Heiman H, Artiga S. Beyond Health Care: The Role of Social Determinants in Promoting Health and Health Equity. Kaiser Family Foundation; 2015.

12. Beck AF, Simmons JM, Huang B, Kahn RS. Geomedicine: area-based socioeconomic measures for assessing risk of hospital reutilization among children admitted for asthma. Am J Public Health 2012;102:2308-14.

13. Auger KA, Kahn RS, Simmons JM, et al. Using address information to identify hardships reported by families of children hospitalized with asthma. Acad Pediatr 2016; e-pub ahead of print 9 July 2016.

14. Henize AW, Beck AF, Klein MD, Adams M, Kahn RS. A road map to address the social determinants of health through community collaboration. Pediatrics 2015;136:e993-1001.

15. Beck AF, Klein MD, Schaffzin JK, Tallent V, Gillam M, Kahn RS. Identifying and treating a substandard housing cluster using a medical-legal partnership. Pediatrics 2012;130:831-8.

16. Gase LN, Schooley T, Lee M, Rotakhina S, Vick J, Caplan J. A practicegrounded approach for evaluating health in all policies initiatives in the United States. J Public Health Manag Pract 2016; e-pub ahead of print 02 September 2016.

17. Lynn J, Oppenheimer S, Zimmer L. Using public policy to improve outcomes for asthmatic children in schools. J Allergy Clin Immunol 2014;134:1238-44.

18. Centers for Medicare and Medicaid Services: State Innovation Models Initiative: General Information. Accessed 10 August 2016. https://innovation. cms.gov/initiatives/state-innovations/.

19. Centers for Medicare and Medicaid: Accountable Health Communities Model. Accessed 10 August 2016. https://innovation.cms.gov/initiatives/ AHCM. 